\title{
Job dissatisfaction among certified adapted physical education specialists in the USA
}

\author{
Lucie Ješinová*, Miroslava Spurná, Martin Kudláček, and Jana Sklenaříková \\ Faculty of Physical Culture, Palacký University, Olomouc, Czech Republic
}

Copyright: (C) 2014 L. Ješinová et al. This is an open access article licensed under the Creative Commons Attribution License (http://creativecommons.org/licenses/by/4.0/).

Background: Professionals working in the area of special education are exposed to the unique situation of occupational stress. Adapted physical education teachers are experiencing several symptoms of the burnout phenomenon. Objective: The purpose of this study was to identify factors causing job dissatisfaction among certified adapted physical education specialists in the USA. Methods: The survey was developed based on: (a) Herzberg's (1959) theory of job satisfaction, and (b) a pilot study, which examined specific factors of job dissatisfaction among adapted physical education (APE) teachers in the USA. The survey consisted of three parts: (a) demographic information, (b) paired comparison of nine general factors which could cause job dissatisfaction, and (c) paired comparison of ten APE specific factors which could cause job dissatisfaction. The participants were 113 certified adapted physical education specialists (CAPES) (88 females, 25 males), a 38\% return rate of all mailed surveys. Results: The results indicated that $39 \%$ of CAPES have seriously considered another job outside of APE and 26\% of CAPES have actively searched for job outside of APE in the last two years. 113 CAPES indicated the general factors that they found the most dissatisfying in their job (listed accordingly to rank, frequency and percent of times chosen, $N$ for each factor $=1017$ ) were working conditions $(644,71 \%)$; policies and administration $(619,68 \%)$; interpersonal relationship with supervisors (552, 61\%); supervision (484, 54\%); salary (404, 45\%); interpersonal relationship with subordinates (404, 45\%); benefits on job (301,33\%); interpersonal relationship with peers (293, 32\%); and job security (245, 27\%). 110 CAPES indicated the APE specific factors they found the most dissatisfying on their job (listed accordingly to rank, frequency and percent of times chosen, $N$ for each factor $=990)$ were paperwork $(687,69 \%)$; scheduling $(659,67 \%)$; facilities (617, 62\%); individualized education plan meetings (464, 47\%); travel (450, 45\%); number of students (429, 43\%); equipment (417, 42\%); variability of disabilities (381,38\%); severity of disabilities (357, 36\%); and home base (353, $36 \%)$. Conclusion: It appears that the efforts should be focused in teacher preparation and in-service support in the areas related to cooperation and communication with school administrators.

Keywords: teachers, occupational stress, special education, disabilities

\section{Introduction}

Educational research has produced several models intended to conceptualize occupational stress, burnout, job satisfaction and dissatisfaction. Professionals working in the area of special education are exposed to unique situation of occupational stress. One of the earliest and most influential theorists was Herzberg (1966), who proposed that job satisfaction and dissatisfaction are independent factors, with job satisfaction being derived from the nature of the work performed (achievement, recognition and the work itself), and job

\footnotetext{
* Address for correspondence: Lucie Ješinová, Department of Adapted Physical Activity, Faculty of Physical Culture, Palacký University, tř. Míru 115, 77111 Olomouc, Czech Republic. E-mail: lucie.jesinova@upol.cz
}

dissatisfaction resulting largely from the circumstances in which the work is conducted (e.g. resources, interpersonal relationships, salaries and working conditions).

In 1962 Rudd and Wiseman reported a study that investigated the level of job satisfaction and the sources of job dissatisfaction for a group of teachers in the UK.

Research on teachers' job satisfaction and dissatisfaction has continued (e.g. Borg \& Riding, 1991; Fraser, Draper, \& Taylor, 1998; Rhodes, Nevill, \& Alan, 2004), about a multivariate approach (Koustelios \& Tsigilis, 2005), with related frameworks such as teacher stress (e.g. Jepson \& Forrest, 2006; Kyriacou, 2001) and teacher burnout (e.g. Abel \& Sewell, 1998; Goddard, O'Brien, \& Goddard, 2006) receiving considerable attention in recent years. Teachers view job dissatisfaction as principally contributed to by work 
overload, poor pay and perceptions of how teachers are viewed by society. For example, researchers such as Hargreaves (1994) and Nias (1989, 1996) mention a number of factors that subvert a teacher's sense of job satisfaction and are related to feelings of loss, disillusionment, vulnerability and negative perceptions of self-worth - the monotony of daily routines, a lack of motivation and discipline on the students' part and a lack of support and appreciation from colleagues and administration. These factors are associated with some of the reasons that teachers leave the profession (Farber, 1991; Friedman \& Farber, 1992; Travers \& Cooper, 1996; Vandenberghe \& Huberman, 1999).

Several studies (e.g., Fimian \& Blanton, 1986; Tatsuse \& Sekine, 2013) have focused on stress and job dissatisfaction as explanatory factors in motivating people to abandon their careers. Among teachers, a strong inverse relationship between levels of stress and job satisfaction has been reported (Sutton \& Huberty, 1984). The connection between job stress and satisfaction has particularly been observed within special education (Eichinger, 2000). Occupational stress is the effect of task demands that teachers face in the performance of their professional roles and responsibilities. Frequent and intense periods of stress are antecedents to attributional, behavioral, physiological, and psychological responses. Over a period of time, the cumulative effect of these responses will influence a teacher's commitment to remain in the classroom and the teaching profession. Eventually, the level of stress being experienced may reach a condition described as "burnout". Stress and burnout constitute one set of factors that directly influences teacher attrition, current staffing patterns, and the quality of educational and related services for students with special needs (Maslach \& Jackson, 1981).

Wisniewski and Gargiulo (1997) emphasized the probable increase in teacher stress given the potential heterogeneity within the classroom while educators maintain disability-specific categorical endorsements. Sloan Nichols (1997) in her study applied the Maslach Burnout Inventory (Maslach \& Jackson, 1981) Educators Survey which measured degrees of burnout on three scales - emotional exhaustion, depersonalization, and personal accomplishment which collected background and organizational factors (Awa, Plaumann \& Walter, 2010). Results indicated that the number of heterogeneous disability categories and the number of students per caseload were not statistically significant to degrees of burnout. As the proportion of emotionally impaired students increased, the degree of depersonalization was significant. Dissatisfaction with university preparation, opportunities for professional development, and discontentment with social supports were organizational factors with statistical significance for increasing degrees of burnout. DePaepe, French, and Lavay (1985) found that adapted physical education teachers are experiencing several symptoms of the burnout phenomenon. The purpose of their study was to identify factors causing job dissatisfaction among certified adapted physical education specialists (CAPES). Based on their results the subjects exhibited several symptoms that are related to the burnout phenomenon. Furthermore, these symptoms are characteristically high throughout the school year. It was concluded that special physical educator supervisors should design appropriate strategies to prevent or reduce these symptoms. Not only would this have a positive effect on teaching behavior but it would in turn improve student leaning.

Wisniewski and Gargiulo (1997) in their article presented one possible re-conceptualization of the burnout paradigm. Most importantly, this model may make it easier to understand how intervening variables change the teacher as well as how the teacher may change the environment. The model presented in their study may not only relate the specific process that leads to burnout but also describe how specific interventions (mentorships, focus groups, relaxation techniques, etc.) affect intervening variables (fatigue, productivity, attitudes, etc.). Kilgore and Griffin (1998) in an interview study of beginning special educators found that novice special educators reported different problems from their beginning colleagues in general education. They often described themselves as insufficiently prepared, frustrated, and exhausted. The compounded pressures unique to inexperienced special educators have also been noted by Rosenberg, O'Shea, and O’Shea (1998). Küçüksüleymanoğlu (2011) worked on determine whether burnout levels of special education teachers working with hearing, orthopedic and mentally impaired students in Bursa, Turkey differ according to some independent variables such as gender, family status, years of teaching experience, educational background and school type.

The type of school has an influence on teacher stress. The majority of studies in this area have considered the effects of teaching in special education (Nguyen, 2012). Litt \& Turk (1985) defined physical educator teachers stress as the experience by teachers of unpleasant, negative emotions and distress that exist when the problems confronting teachers threaten their well-being, and surpass their ability to resolve these problems.

DePaepe, French, and Lavay (1985) found that in addition to the factors experienced by special educators, special physical educators must contend with inadequate allocation of space within the school. 
Crawford (2011) described that teachers involved in primary mainstream and specialist settings expressed a grave lack of self-confidence, due to lack of training, in the delivery of Adapted Physical Activity (APA) programs to children with special educational needs. Freeman and Gray (1987) pointed out that for children with special needs, teachers have to play not only the role of the teacher, but also the role of a nurse and a mother. Within the school, the teachers are clearly challenged by the pupils' special needs. In addition to that, these teachers also have difficulties with interprofessional cooperation and parental participation. According to Cook and Leffingwell (1982), special physical educators have been known to teach in hallways, in rooms left vacant during other teachers' conference periods, and in rooms far removed from the main school area. This investigation was conducted to determine if the concept of burnout is relevant in special physical educators, and whether the level of burnout builds up over the time.

The purpose of this study was to identify factors causing job dissatisfaction among certified adapted physical education specialists in the USA.

\section{Methods}

The survey was developed based on Herzberg's (1959) theory of job satisfaction, and (b) a pilot study, which examined specific factors of job dissatisfaction among APE teachers in the USA. The survey consisted of three parts: (a) demographic information, (b) paired comparison of nine general factors which could cause job dissatisfaction [working conditions, company policies and administration, interpersonal relationship with supervisors, supervision in technical, instructional and planning matters, salary, interpersonal relationship with paraprofessionals/aids, benefits of job (health insurance, retirement plan, etc.), interpersonal relationship with peers and job security], and (c) paired comparison of ten APE specific factors which could cause job dissatisfaction. The validity of developed survey was analyzed by content related expert validity. Criteria for the expert selection were: (a) Ph.D. with emphasis on adapted physical education, (b) knowledge of APE structure (foundation for CAPES certification) and (c) minimally 5 years of experience in work in the area of adapted physical education in public schools or universities. Based on the above described criteria, three experts from the USA were selected. Participants were 113 certified adapted physical education specialists - CAPES ( 88 females, mean age 39.54; 25 males, mean age 42.65) with three of them filling only general part of the survey. The survey study was distributed via traditional post mail list serve from CAPES database. CAPES database is internal database with addresses of certified adapted physical educators from the whole USA. One hundred thirteen respondents represented $38 \%$ return rate. In all results we consider frequency above $50 \%$ as a problem; frequency between $40 \%$ and $50 \%$ as a small problem and less frequency as negligible problem.

\section{Results}

Highly above other areas of general concept of job dissatisfaction are inappropriate working conditions with $71 \%$ of CAPES having problems with them closely followed with $68 \%$ by perception of school policies and administration. Considering another two negative factors are interpersonal relationship with supervisors $(61 \%)$ and supervision in technical, instructional and planning matters (54\%) are also related to areas associated with school districts' management, we should stress out the perception of poor working conditions and limits associated with the management of schools and school districts. On the other hand most CAPES have not perceived problems related to interpersonal relations with paraprofessionals $(45 \%)$ and peers $(32 \%)$. Most of them also found appropriate job related benefits and job security (negative scores only in around $30 \%$ )

Results from attributes related specifically to jobs of adapted physical educators revealed similar and complementary finding to the perceptions of general conditions. Among the top two places we found two areas directly connected with administrative issues with too much paperwork demands being perceived as biggest problem with $69 \%$ followed by perception of lack of priority for APE scheduling within the schools (Table 2 ). The only other factors scoring above $50 \%$ was the lack of teaching space with $62 \%$. Four issues perceived as smaller problem with the perception between 40 to $50 \%$ percent were: (a) lack of involvement in individualized education plan process, (b) amount of traveling time, (c) large class sizes and (d) lack of adequate equipment. Surprisingly severity (36\%) and heterogeneity $(38 \%)$ of students with disabilities did not place were high in comparison with other problems. The school related identity and cooperation with peers (36\%) was also not considered to be the issue adding to the occupational stress of CAPES. 
Table 1

Ranking of Herzberg factors attributed to job dissatisfaction for CAPES

\begin{tabular}{lcc}
\hline Attributes associated with job dissatisfaction & Total score & $\%$ \\
\hline Working conditions & 644 & 71 \\
Company policies and administration & 619 & 68 \\
Interpersonal relationship with supervisors & 552 & 61 \\
Supervision in technical, instructional and planning matters & 484 & 54 \\
Salary & 404 & 45 \\
Interpersonal relationship with paraprofessionals/aids & 404 & 45 \\
Benefits of job (health insurance, retirement plan, etc.) & 301 & 33 \\
Interpersonal relationship with peers & 293 & 32 \\
Job security & 245 & 27 \\
\hline
\end{tabular}

Note. Range of possible answers scores is related to number of items in pairwise comparison and total number of respondents as each attribute is compared with all other attributes on the list. Therefore for the comparison of nine attributes maximum score (representing maximum dissatisfaction) is $9 \times 113=1017$.

Table 2

Ranking of APE specific factors attributed to job dissatisfaction for CAPES

\begin{tabular}{lcc}
\hline Attributes associated with job dissatisfaction & Total score & $\%$ \\
\hline Too much of paperwork (including IEP reports) & 687 & 69 \\
Lack of priority for APE in scheduling within the schools & 659 & 67 \\
Lack of teaching space & 617 & 62 \\
Not involved or not included in IEP process & 464 & 47 \\
Amount of time spent and distance going to schools & 450 & 45 \\
Large class size and high weekly student workload & 429 & 43 \\
Lack of adequate equipment to meet the needs of students & 417 & 42 \\
APE students are very heterogeneous, variability is disconcerting & 381 & 38 \\
APE students have severe disabilities & 357 & 36 \\
Lack of school identity, interaction with other teachers & 353 & 36 \\
\hline
\end{tabular}

Note. Range of possible answers scores is related to number of items in pairwise comparison and total number of respondents as each attribute is compared with all other attributes on the list. Therefore for the comparison of nine attributes maximum score (representing maximum dissatisfaction) is $9 \times 110=990$.

\section{Discussion}

Problems that certified adapted physical educators do not seem to be able to overcome by their own efforts (Litt \& Turk, 1985) are mainly issues related to the school administration: (a) perception of school policies and administration; (b) interpersonal relationship with supervisors; (c) supervision in technical, instructional and planning matters together with perception; (d) inadequate demand on paperwork and (e) the lack of priority for scheduling issues can be successfully addressed by school administrators without the allocation of too many extra financial resources. Issue related to inadequate teaching facilities is in accordance with findings of similar studies from the USA (Cook \& Leffingwell, 1982; DePaepe, French, \& Lavay, 1985) more difficult to resolve, but necessary to assure appropriate quality physical education for students with special educational needs and to prevent APE teacher's burnout. Crawford (2011) examined the current status of APA in primary and special school settings in Ireland. Key findings indicated that respondents wished to participate in further specific training in APA leading to a formal qualification and expressed dissatisfaction with initial teacher training, minimal ongoing in-service provision and limited teaching resources for the provision of quality APA to children with special educational needs. 
Indication that job satisfaction is primarily affected by "job itself" followed by "supervision" and "working conditions", whereas burnout is affected by "personal accomplishment" and "emotional exhaustion" (Koustelios \& Tsigilis, 2005).

The results of the studies could be used to determine the need for remedial techniques to reduce the level of burnout if it does exist (Bradfield \& Fones, 1984; Fimian, 1980; Taylor \& Salend, 1983). Küçüksüleymanoğlu (2011) revealed the fact that teachers working in special education schools had been experiencing burnout at very high levels. When burnout levels were investigated with respect to the type of the schools where the teachers work, significant differences were found in all subscales. To overcome burnout syndrome, it is necessary to train qualified teachers not only psychologically but also physiologically. Intervention programs against burnout are beneficial and can be enhanced with refresher courses. Better implemented programs including both person and organization - directed measures should be offered and evaluated (Awa, Plaumann, $\&$ Walter, 2010). Our finding in relative low significant contribution of severity and heterogeneity of needs among students with disabilities to teachers' burnout were in agreement with the study of special educators by Sloan Nichols (1997). Therefore it appears that the efforts should be focused in teacher preparation and inservice support in the areas related to cooperation and communication with school administrators. We should also consider the most effective ways how to communicate with the top administration representatives from school districts in order to assure better cooperation with adapted physical educators and commitment to serving students with special educational needs in physical education.

We can find similarity to Goetzinger (2006) with the survey pertaining to the teacher's amount of experience, demographics, types of certification, and teacher's caseload. Following a regression analysis, findings indicated that amount of teaching experience; types of teachers' certification and school size were non-significant. The findings from this study reflect the fact that the role of the special education teacher's job continues to be challenging in the area of inappropriate working conditions; perception of school policies and administration and interpersonal relationship (Embich, 2001). According to Goetzinger (2006), teachers are working with this particular problems such as too much paperwork and perception of lack of priority for APE scheduling within the schools. Implications of these findings for school support programs, specific resources in the working environment, and supply of special education teachers are suggested.
As with any research, a number of threats may have impacted the internal validity of the study. Some research participants dropped out due to lack of interest in completing the questionnaire, thus failing to return the survey to the principal investigator. Maintaining the participants' interest in completing the instrument was beyond the researcher's control, nonetheless every attempt was made to mediate the questionnaire in a format that facilitated ease of completion. Another limitation of the study was that special education teachers had to complete paperwork to participate in this study. Since these teachers report that the excessive amount of time they have to spend on paperwork in their jobs is a major reason they leave the field, making them complete additional paperwork may have unduly influenced the results and therefore the sample may represent biased findings.

\section{Conclusion}

Although the majority of the findings were non-significant, this could be viewed as a positive outlook for the USA in the area of special education specifically job dissatisfaction. Because these teachers are more focused in the various areas of special education and they tend to have more experience in the field, they have the tools to be successful when dealing with dayto-day concerns. More research is needed to examine why teachers choose to stay in the area of special education.

\section{Acknowledgment}

This study was supported by a grant from the European Social Fund and the Government of the Czech Republic (No. CZ.1.07/2.3.00/30.0041) "Support for the creation of excellent research teams and intersectoral mobility at Palacký University in Olomouc II".

\section{References}

Abel, M. H., \& Sewell, J. (1999). Stress and burnout in rural and urban secondary school teachers. Journal of Educational Research, 92, 287-293.

Awa, W., Plaumann, M., \& Walter, U. (2010). Burnout prevention: A review of intervention programs. Patient Education \& Counseling, 78, 184-190. doi:10.1016/j. pec.2009.04.008

Borg, M. G., \& Riding, R. J. (1991). Occupational stress and satisfaction in teaching. British Educational Research Journal, 17, 263-281. 
Bradfield, R. H., \& Fones, D. M. (1984). Recipe for burnout: The special education teacher's diet. Academic Therapy, 19, 499-504.

Cook, J. M., \& Leffingwell, R. J. (1982). Stressors and remediation techniques for special educators. Exceptional Children, 49, 54-59.

Crawford, S. (2011). An examination of current adapted physical activity provision in primary and special schools in Ireland. European Physical Education Review, 17, 91-109.

DePaepe, J., French, R., \& Lavay, B. (1985). Burnout symptoms experienced among special physical educators: A descriptive longitudinal study. Adapted Physical Activity Quarterly, 2, 189-196.

Eichinger, J. (2000). Job stress and satisfaction among special education teachers: Effects of gender and social role orientation. International Journal of Disability, Development, and Education, 47, 399-412.

Embich, J. L. (2001). The relationship of secondary special education teachers' roles and factors that lead to professional burnout. Teacher Education and Special Education, 24, 58-69.

Farber, B. A. (1991). Crisis in education: Stress and burnout in the American teacher. San Francisco, CA: Jossey-Bass.

Fimian, M. J. (1980). Stress reduction: Techniques for teachers. The Pointer, 24, 64-69.

Fimian, M. J., \& Blanton, L. P. (1986). Variables related to stress and burnout in special education teacher trainees and first-year teachers. Teacher Education and Special Education, 9, 9-21.

Fraser, H., Draper, J., \& Taylor, W. (1998). The quality of teachers' professional lives: Teachers and job satisfaction. Evaluation and Research in Education, 12, 61-71.

Freeman, A., \& Gray, H. (1987). Teaching without stress. London: Paul Chapman.

Friedman, I. A., \& Farber, B. A. (1992). Professional selfconcept as a predictor of teacher burnout. Journal of Educational Research, 86, 28-35.

Goddard, R., O'Brien, P., \& Goddard, M. (2006). Work environment predictors of beginning teacher burnout. British Educational Research Journal, 32, 857-874.

Goetzinger, A. (2006). Burnout among special educators: Do experience, certification, caseload, and school size make a difference? (Unpublished doctoral dissertation). The University of Oklahoma, Graduate College, Oklahoma City, OK.

Hargreaves, A. (1994). Changing teachers, changing times. London: Cassell.

Herzberg, F. (1966). Work and the nature of man. New York, NY: Wiley.

Herzberg, F., Mausner, B., \& Snyderman, B. (1959). The motivation to work. New York, NY: John Wiley and Sons.

Jepson, E., \& Forrest, S. (2006). Individual contributory factors in teacher stress: The role of achievement striving and occupational commitment. British Journal of Educational Psychology, 36, 362-378.

Kilgore, K. L., \& Griffin, C. C. (1998). Beginning special educators: Problems of practice and influence of school context. Teacher Education and Special Education, 21, 155-173.
Koustelios, A., \& Tsigilis, N. (2005). The relationship between burnout and job satisfaction among physical education teachers: A multivariate approach. European Physical Education Review, 11, 189-203. doi: 10.1177/1356336x05052896

Küçüksüleymanoğlu, R. (2011). Burnout syndrome levels of teachers in special education schools in Turkey. International Journal of Special Education, 26, 53-63.

Kyriacou, C. (2001). Teacher stress: Directions for future research. Educational Review, 53, 27-35.

Litt, M. D., \& Turk, D. C. (1985). Sources of stress and dissatisfaction in experienced high school teachers. Journal of Educational Research, 78(3), 178-185.

Maslach, C., \& Jackson, S. (1981). The measurement of experienced burnout. Journal of Occupational Behavior, 2, 99-113.

Nguyen, H. (2012). General education and special education teachers collaborate to support English language learners with learning disabilities. Teacher Education, 21, 127-152.

Nias, J. (1989). Primary teachers talking: A study of teaching and work. London: Routledge.

Nias, J. (1996). Thinking about feeling: The emotions in teaching. Cambridge Journal of Education, 26, 293-306.

Petkovic, N., Macesic, D., Balos, V., Misic, M., \& Djordjevic, M. (2012). Burnout syndrome among special education professionals. HealthMed, 6, 3403-3417.

Rhodes, C., Nevill, A., \& Alan, J. (2004). Valuing and supporting teachers: A survey of teachers' satisfaction, dissatisfaction, morale and retention in an English local education authority. Research in Education, 71, 67-80.

Rosenberg, M. S., O’Shea, L., \& O’Shea, D. (1998). Student teacher to master teacher. New York, NY: Macmillan.

Rudd, W. G. A., \& Wiseman, S. (1962). Sources of dissatisfaction among a group of teachers. British Journal of Educational Psychology, 32, 275-291.

Sloan Nichols, A. (1997). Burnout among special educators having heterogeneous student populations in self-contained assignments across the state of Michigan (Unpublished doctoral dissertation). Wayne State University, Graduate School, Detroit, MI.

Sutton, G. W., \& Huberty, T. J. (1984). An evaluation of teacher stress and job satisfaction. Education, 105, 189-192.

Tatsuse, T., \& Sekine, M. (2013). Job dissatisfaction as a contributor to stress-related mental health problems among Japanese civil servants. Industrial Health, 51, 307-318.

Taylor, L., \& Salend, S. (1983). Reducing stress-related burnout through a network support system. The Pointer, 27, $5-9$.

Travers, C. J., \& Cooper, C. L. (1996). Teachers under pressure: Stress in the teaching profession. London: Routledge University Press.

Vandenberghe, R., \& Huberman, A. M. (1999). Understanding and preventing teacher burnout: A sourcebook of international research and practice. Cambridge: Cambridge University Press.

Wisniewski, L., \& Gargiulo, R. (1997). Occupational stress and burnout among special educators: A review of the literature. The Journal of Special Education, 31, 325-346. 